\title{
Analysis of Current Conditions of BOT Contracts and Proposed the Strategies to Increase its Efficiency
}

\author{
Heydar Davoodian $^{1}$, Seyed Mahdi Seyed Kolbadi ${ }^{2, *}$ \\ ${ }^{1}$ Department of management, Sari Branch, Islamic Azad University, Mazandaran, Iran \\ Email address: mahdi_kolbadi@sina.kntu.ac.ir , telephone number:00989113701146 \\ ${ }^{2}$ Department of Civil Engineering, KN. Toosi University of Technology, Tehran, Iran \\ *corresponding author: mahdi_kolbadi@sina.kntu.ac.ir
}

\begin{abstract}
In our country, due to the shortage of governmental financial resources and also increase of the range of the need for infrastructural facilities in various sectors, using contracts that are somehow seeking privatization methods and use capitals of the nongovernmental sector, whether domestic or foreign, is developing. Given the laws available in the country, which will be mentioned in this research, the BOT method has more compatibility with the laws of the country in comparison with other similar methods. Therefore, due to the increase of the application of BOT contracts in the country and usage of foreign capitals in the construction and the development of the infrastructural facilities in various sectors and absence of sufficient information and sources in this field, doing complementary studies in this respect is especially important. In this research, at first by studying the importance of development of infrastructural structures, the discussion of privatization and usage of the capitals of the private sector and also foreign investments in the construction and development of the infrastructural structures have been especially reviewed in the shape of BOT contracts. As we continue, by presenting a complete introduction of BOT contracts and the laws associated with them, some examples of the application of this method and the laws of executing it have been reviewed in various countries. Later, by studying the current laws in the country, the application of this method in the country and the obstacles on the way have been referred to.
\end{abstract}

Keywords: Financing, Privatization, BOT, Rules and Regulation, Increase of Efficiency

\section{Introduction}

Meeting the purpose of social and economic development and growth in each country requires formation of capital for providing the financial sources needed for infrastructural plans. Theoretically, there is no doubt that capital as the generator of economic growth and development is one of the fundamental principles of economy. In fact, capital is the initiator of economic growth and flourishment and it's what keeps it going. Our country has no way than to wonderfully increase the rate of its capitals to renew itself after incidents such as war, to be in line and in coordination 
with the accelerating process of economic growth in Asia especially the countries in the Southeast of Asia.

Since the domestic facilities are not sufficient for capital formation in the countries to meet the great economic purposes, thus using foreign financial sources as the supplement for domestic sources and tools in order to pave the way for foreign investments and development and reinforcement of the productive forces and capacities seems unavoidable and essential. Using foreign financial sources through borrowing, subsequent to the debt crisis occurring in the world in 1982 and its negative economic - political consequences, conveyed the message that using foreign loans and credits without any terms and conditions leads to failure in such a way that currently, this method of financing has been put away in most countries all over the world.

It is natural that domestic investment shall be given a role and part in development, because as these capitals enter the process, not only the gaps existing in the economy of the country become filled, but also some opportunities are created for transferring productive technology and management and reaching world markets and many other advantages become possible.

Our country, given the crucial need for constructing and developing infrastructural facilities and subsequent to it the need for borrowing loans to cover the costs, has been seeking strategies for attracting foreign capitals through different methods. Privatization-based policies and reduction of governments' being in charge of various economic activities especially development of infrastructural structures and also insufficiency of the capitals of the domestic private sector for covering these costs, has made the government to turn into modern contract methods with the purpose of attracting foreign capitals.

Numerous plants have reached the stage of exploitation in the country over the past few years through foreign investments and although there are a few of them, they showed that foreign financial sources and also productive technology and knowledge are essential for the effective improvement and efficiency of the plans [27].

As it has already been mentioned, methods such as BOT which is the subject of this research are different types of foreign investment methods which have been created with the purpose of financing infrastructural projects and in the respect of privatization purposes. For this purpose, most of the laws dominating this method are the laws that exist in the field of foreign investment which shall be reviewed for facilitating the application of the methods such as BOT so that if needed, some items would be added to them or some changes would be made. Given that the laws monitoring foreign investment in the country in fact provides the substrate for using BOT contracts in the country, in this section, it is attempted to review the process of reformation of these laws in the respect of attracting foreign capitals more and more by studying the laws of the country in the area of foreign investment and as it goes on, by studying the laws associated with BOT contracts in the country, the existing obstacles and limitations would be identified and proper practical strategies would be presented.

\section{Review}

\subsection{Review of the process of foreign investment in Iran}

In Iran, the history of foreign investment has been more or less formed in parallel with the evolutions of investment in various countries of the world but the excursion of its evolutions and the fluctuations created in the current of the entrance of more foreign capitals have been affected by the 
special conditions and evolutions of the country in various time periods and the economic purposes have not been the only thing considered in this process.

A brief overlook at the process of the foreign investment in the country shows that initial investment in Iran has mostly been done as the granting of credit and signing contracts with powerful people or institutes and given that the nature of these investments, most of the interests obtained from the investment have belonged to the foreigner side of the contract.

With the issuance of the law of attracting and supporting foreign capitals in the year 1955, a turning point was created in the history of foreign investment in Iran. Throughout the years 197893, given the special conditions of that time, the entrance of foreign capitals to the country almost stopped. However, since 1993, the entrance of foreign capital to the country started again slowly.

In the time interval of 1993 to 1998, the government attempted to provide the proper field for attracting foreign capital and in this respect, the law regarding how to manage Iran's business industrial free zone according to the article 8 of which allows those organizations and companies to sign the essential contracts with domestic and foreign natural and legal persons, was approved. In this law, facilities which have been considered for foreign investment in these zones among which a 15-year tax exemption from the payment of taxes and assets of natural and legal persons who do economic activities in the zone.

Generally, great efforts have been made in this period for attracting foreign capitals. Also, in this period, by approving the law of the second program of the economic, social and cultural development of the country, an important step was taken to facilitate attraction of foreign investment.

During the time interval starting in 1998 and ending in the 2002 and during the third program of the economic, social and cultural development, the issue of foreign investment and facilitation of the conditions of its implementation has also been considered by policy makers. Although like the past years, it hasn't gone through a wonderful change. Of course, except for the year 1999 in which a sudden mutation has occurred in the volume of the foreign investment in the country, in this period despite the relative increase in the rate of attraction of foreign capitals in the country which was at the same time of the final years of the second program; nonetheless, Iran has not yet moved in terms of attraction of foreign sources in line with international and regional evolutions and in comparison with the countries with similar economy, ours has acquired less success [1].

In we review the policies that these countries have made and used for entering capital to their country, we see that many factors have been involved here which are: economic liberation policies, adaptation of outward-oriented and market-based economic policies, supporting the private sector, creating socioeconomic reformations, proper infrastructural facilities, stability of economic policies, semi-skilled and cheap human force, the necessary regulation and safety for supporting the capital and interest of foreign shareholders. Therefore, it is necessary for the country to be successful in this regard in the respect of applying these policies given the conditions of the country.

\subsection{Review of the process of foreign investment in Iran}

One of the most important laws existing in the country is the laws of economic, social and cultural development programs which include the great policies of the country. In fact, in these programs, the four-year policies of the country in the area of foreign investments can be studied. 
Whatever is approved in this time interval in the area of foreign investment will be by considering the policies cited in this program.

One of the very important items of the law of the fourth program in association with the BOT contracts refers to the article 24 of this law which has allowed the government to provide the necessary fields through the method cited in paragraph " $b$ " of the article 3 of the law of encouraging and supporting foreign investment in order to implement the law of encouraging and supporting foreign capitals issued in 03/09/2001 in order to attract foreign investment in the respect of economic growth, promotion of technology, promotion of quality of productions, increase of job opportunities and increase exports in the realm of productive activities including industrial, agricultural, infrastructural activities, services and information technology. It is necessary to note that paragraph " $b$ " of the article 3 of the law of encouraging ad supporting foreign investment is the first permit which has issued the permission for the BOT method to be used in various sectors [2].

\subsection{Review of the qualitative purposes expressed in the laws of annual budget}

In the respect of attraction of foreign capitals in the country, other qualitative purposes have been embedded in the laws of annual budget as well as the development programs. Given that the first cited items in the area of foreign investment is traced back to the budget laws of the years 1998 and 1999 and most of these items have been repeated with some reformations in the next years. In following section, the items cited in the budget law of the year 1998 are mentioned: [3]

Paragraph (n), note 2: foundation of new companies by governmental companies was prohibited in 1998. Banks, credit institutes, insurance companies and governmental companies that attempt to form a company through participating in foreign investments (under 50\%) with the purpose of productive activities are the exceptions in this paragraph.

Section (6) of the paragraph (d) of note 29: Oil Ministry is obligated to issue a license for the establishment of a refinery due to the demand of domestic applicants themselves or with a foreign participation (a maximum of $49 \%$ ).

It is necessary to explain that the items such as the granted license cited in the sections (2), (3), (4), (5) and (6) of the paragraph (1) of note (29) of the law of budget of 1999 of the entire country and the sections (1) and (3) of paragraph (L) and paragraph (Sh) of note (29) of the law of budget of 2000 of the entire country and the sections (1-1), (1-2), (5) and (6) of the paragraph (L) of note (29) of law of budget of the year 2001 of the entire country and paragraphs (z), (h), (t) and (l) of the note of the law of budget of the year 2002 of the entire country and paragraph (j) of note (10) and paragraph (z) and (d) of note (16) and (d), (h), (f), (z) and (t) of note 21 of the law of budget of the year 2003 of the entire country with the issued conditions in the year 2004 still remain the same [32].

The most important paragraph of the law of budget of the year 2004, which is associated with the BOT contracts, is the paragraph (1) of note 21 which is associated with foreign currency and money policies has been presented in this section:

In the implementation of the law of encouraging and supporting foreign investment issued in 03/09/2001, the board of ministers is allowed to attempt to attract domestic and foreign investors, with the Iranian investors being the priority, through the mentioned method in paragraph (b) of article (3) of the law of encouraging and supporting foreign investment in order to attract foreign investment in the projects of power generation in hydroelectric, steam, gas, combined cycle, 
pumped storage, new energy and power transmission to the capacity of $12000 \mathrm{MW}$ and refinery construction projects up to the capacity of 300 thousand barrels per day, Tehran's sewage and $\begin{array}{lllllll}\text { establishment of } & 3400 \quad \mathrm{~km} & \text { of } & \text { railways and } & 1300\end{array}$ $\mathrm{km}$ of highway, development and equipment of Imam Khomeini airport and 7 existing international airports, development and equipment of large business ports of the country and supplying rail fleet and telecommunication projects.

\subsection{Review of the qualitative purposes expressed in the laws of annual budget}

In this section, with the purpose of feasibility of the implementation of BOT contracts in the country, we review all of the existing laws in association with this type of contracts and investigate all of the existing executive and legal facilities, supports, obstacles and limitations. Since the BOT contracts have not been implemented in the country and they have just grown in specific sectors including construction and development of power plants and transportation systems such as roads and highways. That is why it is not possible to mention all of the executive and legal limitations, because many of the shortcomings existing in the rules and regulations in association with this kind of contracts become evident at the time of being executed. For this purpose, in this section, it has been attempted to identify the available facilities or obstacles by exploiting the opinions of the designers of this method in the country and by studying the path of implementation of the available BOT contracts and to seek creation of a proper framework for that.

Generally, the laws of the country governing all types of contracts also apply to BOT contracts. The laws associated with the contracts include two parts: a part which is the issue of civil law and the principle of right and obligation is discussed (substantive law) and the other is associated with the procedures of investigating the disputes which is the subject of the civil and criminal procedures (law of procedure) [4].

Basically, according to the article 10 of the civil law, all of the contracts we sign follow the civil law of the country. In other words, our rights and the rights of the other side of the contract (the company that runs the project) regarding the issues associated with the BOT project includes the items cited in the civil law and in the contract and in fact, the generality governing the contract is the civil law itself. For this purpose, all of the foreign investors are required to sign contracts by observing the principles cited in the civil law.

In terms of the acceptance of the judgment system and the Dispute Resolution Council, the investors are not usually interested in accepting it which might be because of the insufficiency of the judgment and procedure laws of Iran regarding BOT projects.

Since the project company, as a foreign recorded company and in the frame of a consortium, enters the contract and attempts to finance, construct, exploit and ultimately transfer the project to the government after passing the stages already mentioned through entering their capital; therefore, BOT projects are considered as an example of foreign investment and all of the laws governing foreign investment must be observed the most important of which is the law of encouraging and supporting foreign capitals; in such a way that the content of this law and its executive regulations along with the civil law of our country is mentioned as the rules and regulations monitoring BOT.

By considering the law of encouraging and supporting foreign investment, the capitals that enter Iran according to this law and consequently the benefits obtained from using these capitals is included in the legal support of the government and all of the rights, exemptions and facilities 
available for the domestic private productive firms and capitals will apply to foreign firms and capitals as well. In fact, project companies, after getting the license, shall be treated as a domestic investor in terms of laws of labor, customs and public laws and criminal regulations, etc.

\section{Methods}

\section{1 limitations and obstacles on the way of execution of BOT contracts}

Due to the fact that no specific law has been defined for BOT contracts in our country, the most basic laws monitoring this type of contracts is the basic law and law of encouraging and supporting foreign investment. For this purpose, the content defined in these laws can have a great effect on the process of execution of these contracts.

a) According to the principle 44 of the constitution, public ownership of all of the infrastructural investments has been considered to be a component of governmental activities (state monopoly); thus, it has exited the area of ownership of the private sector; whereas the BOT projects are invested in by the private sector.

b) According to the principle 139 of the constitution, in case of occurrence of dispute, it is the qualified Iranian judges to hold a hearing for the claim of fair compensation for the damage that has been done which has been guaranteed by the government. And this issue in some cases causes dispute and foreign investors are not interested to deal with the hearings in Iranian courts; but they tend to refer to international judgment. In this regard, in the principle 139 of the constitution, it has been cited that in case a hearing is supposed to be held as an international judgment, the project must be approved by the Islamic Council Assembly and they shall grant the permission for international judgment [34].

Given that the foreign investors basically focus on the income earned from investments after deduction of taxes and other mentioned costs, it is natural that presence of taxes, dues and other public rights including business profit and rights can affect the unessential increase of the investment costs and in some cases the investment motivations might be weakened in the country because of them. Thus, these costs being imposed on investment will lead to the reflection of these costs with the interests belonging to the rate of the supplied services and emergence of a repeated process in the financial turnover of the government especially that they force additional costs on the budget of the government.

In the law of encouraging and supporting the foreign investors, the foreign investors takes advantage of all of the rights, supports and facilities that are available for a domestic investor especially in the discussion of taxes. Given this law, due to the long period of time construction, exploitation and transmission of the projects takes, only the first few years of it has tax exemption and since the foreign investor cannot carefully predict what their tax expenses will be so the risk of high tax expenses and dues is considered a serious obstacle for them.

\subsection{The strategies regarding BOT contracts being executed}

In all law, a wide range of motivations and benefits has been considered for the investors and the investment laws must become applicable for investment with the BOT method which in another form of foreign investment in the infrastructural projects.

By taking the items cited in the previous sections into consideration, in order to prepare a comprehensive and inclusive regulation and law for the execution of BOT contracts in the country, 
it is essential to use the experience of successful countries in the execution of these contracts and the conditions these countries provide for the contracts to be executed in the shortest period of time and taking into consideration the conditions existing in the country and also opinions and recommendations of specialists and authorities in this area.

For this purpose, in this research, by referring to the laws of various countries in this area and also the laws available in the country in the field of attracting foreign capitals and execution of BOT contracts, a questionnaire was prepared and by referring to different organizations and ministries, that are somehow responsible for the execution of the BOT contracts in the country and by using the expert opinions in this field, the effect of these laws in each sector and the obstacles and difficulties existing on the way of execution of these contracts have been reviewed.

In this questionnaire, given the relevant ministry or the institution, some questions have been mentioned in the area of activities done in the respect of using the BOT contracts in that sector and problems on the way of these activities and some strategies have been demanded for these contracts being executed.

Given the obtained results, the following conclusion can be obtained:

In the opinion of authorities and experts of different sectors of the country, in all kinds of projects, given the financial features and long term nature of the BOT contracts, the titles below are especially important in the investment laws of BOT projects:

a) Issues associated with land ownership

b) Issues associated with the dispute resolution reference

c) The right of exchanging local currency to foreign currency

d) Permission to transfer cash to the foreign country with foreign currency

e) Complete repayment of the loans and recoupment of capital in case of adopting policies by the government which leads to the transmission of the project (including expropriation, possession and nationalization)

f) Simple customs methods and granting entrance permission

g) The right of employment and permission of the entrance of foreign nations needed for construction, exploitation and maintenance of the project

h) The right of establishment of the host country for foreign investments

i) Tax systems for foreign investment

j) The right of capital insurance for foreign investment

k) Guarantee against various political incidents such as nationalization and expropriation

The law of encouraging and supporting foreign investment approved in 2002 covers most of the items above and it has become properly compatible with the BOT contracts; but the presence of some of the limitations applied by other laws in the country have created some difficulties on the way of this kind of contracts for which the following strategies are recommended:

For example, this is the case in terms of highways of the ministry of roads, the dues of which are taken by the private sector or the power plants of the ministry of power, the exploitation of which is done by the private sector.

In the field of license for exchanging foreign currency and permission for the capital itself and profit transmission, there are some specific limitations and the Central Bank, with the license issued by the government, grants the permission for the capital itself and its profit to be taken out to the 
determined extent after deduction of taxes and with the rate of the time of its exchange. Payments in Iran can be done with Rials and also with foreign currencies. In some projects, 100 percent of the payment is Rials and the Central Bank can exchange it to foreign currency as much as it has been determined in the contract. For this purpose, given the change of the rate of foreign currency, it is essential to predict the moderation for payments in Rials or payments can be done in foreign currency so that there would be no need to guarantee the exchanges [5].

In the field of dispute resolution reference for observing principle 139 of the constitution, since we have no specific law or a determined legal framework for the BOT projects, foreign investors set this condition at the beginning of signing the contract that we must present them with the directive of the Islamic Council Assembly regarding the permission for international judgment and then sign the contract. However, the problem is that getting this license requires a long process which will lead to a severe delay in the contract and project.

For this purpose, the thing that can be done to solve the problem is to come to an agreement about the reference of international judgment and in case of a disagreement, the Iranian side of the contract must review the directive of the assembly. Therefore, they come to a temporary agreement but in case of a disagreement, if the assembly does not grant this license to the organization or its project, the Iranian side of the judgment will lose because without the directive of the assembly, they are not permitted to participate in an international judgment and the hearing for dispute resolution must be held in Iranian courts [3, 4].

In case of a license being granted, we can visit the ICC international business office located in Paris for dispute resolution and the branches of it which are located in all countries. ICC is an international organization and it is a dispute resolution reference [5].

In order to solve the problem of prohibition of registration of 100-percent foreign companies in the country, given the principle 81 of the constitution, usually the following strategies are used:

Participation of a foreign company in an Iranian company, in which there are Iranian shareholders - even if the foreign partners have $99 \%$ of the shares, thy are considered an Iranian company - will not be considered as a good point for them and there would be no conflict with the constitution.

The other solution for participation is buying control share in which, in addition to the rate of capital to be minimum, the governance of the majority of the capital is not in the statute. With this solution, investors, by having $49 \%$ of the share, can have control over the company and be in charge of it $[1,2]$.

\section{Discussion}

As it has already been mentioned, none of the laws existing in the country completely comply with the conditions of BOT projects and each of them have special defects regarding BOT projects; in the same respect, getting help from a reformation, appendage and supplement to the current law would make filling the gaps existing in the law easier or vice versa, presenting a new text of law would be more impactful.

Some of the governments of countries such as Vietnam, Cambodia, Turkey and Philippine have set special laws for this type of contracts for executing BOT contracts which are considered as the basis of the execution of BOT contracts in these countries along with other laws in these 
countries such as law of supporting foreign investment. In the appendixes 3 and 4, this research has presented 2 examples of these rules and regulations which belong to the countries Cambodia and Vietnam [1].

Generally, strategies building the substrate for the legal framework of the agreements of the BOT project are very different and the legal approach might be in one of the three forms as follows:

a) Open-agreement approach in which the authority granted to the government or the dependent organizations for each BOT project is very flexible.

b) Limited agreement approach in which the legislator determines the basic conditions of the BOT agreements.

c) A wide range of approach in between these two.

Since in Iran, according to the article 44 of the constitution, the private sector cannot own the infrastructural projects and this belongs specifically to the government, the open-agreement approach (first type) cannot be executed in Iran and acceptance of the approach of the third type faces many limitations; however, the limited agreement approach can be recommended as a basic solution.

a) This approach gives the legislator and the government permission to carefully control the development of the infrastructural project and to monitor the realization of the national BOT purposes. Also, it reinforces the authorities in their negotiations with the private sector and it might help reduce the legal costs and time for finalizing the BOT agreements.

b) It helps foreign investors to have easier access to important legal conditions for BOT projects.

c) It prepares the necessary responses to important issues in the BOT projects such as the rights of foreign investors, purchasing methods and the essential guarantees.

d) It clarifies the motivations and supports that must be created by the governments and gives them legal credit.

e) It is indicative of the government's commitment for developing the BOT projects in the country for potential investors.

f) By reducing the number of items that must be embedded in the contract, the project will become more economical in terms of the costs of the draft of the contracts of the project and saves the time needed for them.

g) If a special law for BOT is executed based on the limited agreement approach, the risk of investors due to issues such as vagueness of the tax system and its costs and exemptions and the issues associated with the environment, customs dues and other expenses will reduce greatly and it makes analysis of the cost-benefit and economic justification possible for the foreign investors and those who grant loans.

\section{Conclusion}

Given the examples of the contracts presented in the appendixes and by taking the limitations in the rules, regulations and the law of encouraging and supporting foreign investment into consideration, a definition in proportion with the project can be found for each of these items.

It might be very suitable to issue a law for this type of projects, which means to define and issue a law which generally includes the items above, as it has also been cited in the BOT laws of the other countries, it can be considered as a great help in the growing process of the application of 
this type of contracts in the country. However, due to the variety of the projects which can be executed by using this method and the special features of each of them, it seems that it is necessary for various institutions and ministries to attempt to prepare its executive regulation by observing this law and by taking the feature of the projects in the sector associated with themselves into consideration.

\section{References}

[1] Wagner, A., Bajsić, I., Fajdiga, M. (2004). Measurement of the surface-temperature field in a fog lamp using resistance-based temperature detectors. Strojniški vestnik - Journal of Mechanical Engineering, vol. 50, no. 2, p. 72-79.

[2] Hafeznia, Mohammadreza (2009). An introduction to the research method in Humanities. 16th edition, Tehran: Samt publication.

[3] Faghihi, Abolhassan and Moosavi Kashi, Zohreh (2010). Efficacy (effectiveness and efficiency) measurement model in Iran's governmental services sector. Journal of governmental management, 2nd period, 4th issue, spring and winter, Pp 107-126.

[4] Najmi Nia, Reza; Salehi, Mohammadreza (2012). Review of the effect of intellectual capital in creation of competitive advantage of the insurance company of Isfahan province. Fourth international conference on banking services marketing in the center of international conferences of Media, October of 2012.

[5] Camisón, César. And Villar-López, Ana. (2011). Non-technical innovation: Organizational memory and learning capabilities as antecedent factors with effects on sustained competitive advantage. Industrial Marketing Management. 40 (2011). 1294-1304.

[6] Hazen, Benjamin and Terry Anthony (2012). Toward creating competitive advantage with logistics information technology. International Journal of Physical Distribution \& Logistics Management. Vol. 42. No. 1. 8-35. 